Journal of Chemical Health and Safety

Safety in Nanotechnology Research

\title{
Occupational Medicine Implications of Engineered Nanoscale Particulate Matter
}

Richard J. Kelly

Materials Sciences Division, Lawrence Berkeley National Laboratory

RJKelly@lbl.gov / 1 Cyclotron Road, MS67r3207, Berkeley CA 94720

Ph: 510-486-4088 / Fax: 510-486-7424

\begin{abstract}
The imminent nanotechnology revolution promises dramatic advancements in science, technology, medicine and society as a whole. First generation products containing engineered nanoscale materials are already appearing in the marketplace, while more sophisticated products are being developed in laboratories around the world. Researchers and manufacturing employees are potentially exposed to dispersible nanoscale particulate matter via inhalation, ingestion and skin contact. Preliminary research indicates that in some cases nanoparticulate matter may be more toxic than other forms of the same or similar material. Application of the classical tools of occupational medicine and industrial hygiene is hampered by the lack of consensus guidelines for medical monitoring, exposure assessment, and exposure control.
\end{abstract}




\section{Introduction}

A revolution is underway in academic and industrial laboratories and factories around the world, where developments in nanotechnology promise a huge range of benefits for science, technology, and society. More than evolutionary, new nanoscale materials will likely prove revolutionary in many fields. This revolution will have a dramatic impact in engineering, materials sciences, chemistry, computer technology, aerospace, medicine and biological sciences, as well as a wide range of manufacturing. Potential applications of these new materials are wide open to innovation.

"Nanotechnology" is most generally defined as the intentional manipulation of matter to form novel structures with one or more dimension or features less than $100 \mathrm{~nm}$. In the broadest sense nanotechnology includes work at the nanoscale in the fields of inorganic and organic chemistry, biochemistry, engineering, electronics and materials science.

While many of the points in this review may be applicable to the entire field of nanotechnology, I focus on engineered dispersible inorganic nanoparticulate matter, hereafter referred to as nanoparticles. These nanoparticles are not attached to a substrate, not part of a larger structure and can be inhaled, ingested or contaminate the skin. They are distinct from naturally occurring environmental ultrafine particles and incidentally produced nanoparticles such as diesel soot, although some engineered structures are also found in air pollution ${ }^{1}$. 
The first generation of "passive" nanoscale materials is now appearing in industrial and consumer products. This includes carbon nanotubes in composite materials used to make sporting equipment, nanoclays in cements and plastics, metals oxides in batteries, paints and sunscreens and fluoropolymers in stain repellant clothing.

Second generation "active" nanomaterials are being developed in laboratories around the world and a few are on the verge of commercialization. Medicine, in particular, is predicted to benefit tremendously from these more advanced materials. Third and fourth generation materials, which include the holy grail of nanotechnology, molecular manufacturing, are still largely beyond the horizon at this time.

Nanoparticle behavior is often strikingly different from the behavior of the chemically similar material of larger particle size. These new properties form the basis for the optimistic claims of nanotechnology pundits. The toxicity of new nanoparticles may also vary qualitatively or quantitatively from that of similar materials at the micro- or macro scale. To date, limited evidence suggests that some materials are uncharacteristically toxic at the nanoscale.

Employees involved in the development, production, distribution and use of these nanoparticles are already potentially exposed to materials of uncertain toxicity. The pubic is also exposed, through the use of topical sunscreens and cosmetics and ultimately through the breakdown of other nanomaterial-containing consumer products. 
The challenge to occupational health professionals is to prevent the development of disease in employees handing these novel nanomaterials despite the lack of toxicological information, consensus exposure standards, air sampling methodologies and medical monitoring protocols. This is particularly difficult in R\&D laboratories, where completely novel materials are developed and processes change frequently.

\section{Sources of Concern}

Nanotechnology involves a wide range of chemistries and structures, many so dramatically new as to have highly unpredictable properties. The range of chemistries used for nanoparticles is vast, as shown in table $1^{2}$. Possible structures are almost unlimited, as suggested by figure 1 which reveals the many different nanoparticles possible for just one chemistry (zinc oxide). In effect, nanoscale structures may be thought of as entirely new chemicals with regard to their potential toxicity.

Unfortunately, it is very apparent that discerning the toxicity of engineered nanoparticles will not be a simple task, as details of chemistry, crystalline structure, morphology, contaminants, size and many other factors must be considered ${ }^{3-5}$. The emerging field of "nanotoxicology" has experienced growing pains due to methodological problems. For example, some early studies of the toxicity of carbon nanotubes were conducted without due consideration of the residual metal catalysts left over from synthesis. This resulted in some inconsistencies in the literature, with the assignment of toxic properties to the nanotubes that may have been the consequence of the synthetic method and residual catalyst $^{6}$. Another early study that purported to expose rodents to single walled carbon 
nanotubes used a material that was only about $50 \%$ nanotubes $^{2}$. A very recent inhalation study that seemed to expose animals to $95 \%$ pure carbon nanotubes used materials that actually were heavily contaminated with other fibrous carbon nanostructures.

\begin{tabular}{|lll}
\hline ELEMENTS USED IN ENGINEERED NANOPARTICLES \\
Aluminum & Animony & Barium \\
Bismuth & Boron & Cadmium \\
Calcium & Carbon & Cerium \\
Chromium & Cobalt & Copper \\
Dysprosium & Erbium & Europium \\
Gadolinium & Gallium & Germanium \\
Gold & Hafnium & Holmium \\
Indium & Iridium & Iron \\
Lanthanum & Lead & Lithium \\
Lutetium & Magnesium & Manganese \\
Molybdenum & Neodymium & Nickel \\
Niobium & Nitrogen & Osmium \\
Oxygen & Palladium & Platinum \\
Potassium & Praseodymium & Promethium \\
Rhodium & Rhenium & Ruthenium \\
Samarium & Scandium & Silicon \\
Silver & Sodium & Strontium \\
Sulfur & Tantalum & Technetium \\
Terbium & Thulium & Tin \\
Titanium & Tungsten & Vanadium \\
Ytterbium & Yttrium & Zinc \\
Zirconium & & \\
\hline
\end{tabular}

Table 1: Elements used in engineered nanoparticles ${ }^{4}$

Figure 1: The many forms of nanoscale zinc oxide may pose diverse health $\operatorname{hazards}^{7}$ 
The traditional experimental models used to evaluate the toxicity of nanoparticles may not be up to the task and may lead to false-positive or false-negative conclusions. The authors of several early in vitro studies using the colorimetric "MTT" assay to measure toxicity of carbon nanotubes to mitochondria failed to recognize that the carbon nanotubes directly interfered with the test, which resulted in flawed conclusions ${ }^{8}$. Species variability is likely to be substantial, for example the pulmonary toxicity of nanoscale TiO2 at high doses differs substantially between rats and most other species including humans ${ }^{9-12}$. More generally, simple, widely employed in vitro assays may not reliably predict in vivo toxicity for many nanoparticles ${ }^{13,14}$.

However, for perspective it is important to remember that people have been occupationally exposed for years to incidental nanoparticles from welding, the production of carbon black and combustion smokes, among others. The safe handling of engineered nanoparticles should build on what we know of the toxicity of these materials.

\section{Emerging Dose Metric: Surface Area}

A dramatic difference in toxicity as a function of particle size is well established in the case of quartz. Quartz particles much larger than $10 \mu \mathrm{m}$ in equivalent aerodynamic diameter are readily removed from the upper and middle part of the respiratory tract where they deposit without consequence. However, smaller particles have the opportunity to reach the alveolar spaces in the lungs, where oxygen is transferred across the capillary membranes into the blood. Once lodged in the alveolar space, the quartz is not readily 
removed by pulmonary defensive mechanisms, is toxic to pulmonary macrophages and initiates a cascade of events characterized by chronic inflammation and ending in lung fibrosis and cancer ${ }^{14,15}$.

Much of the size-specific toxicity of quartz can be ascribed to differential deposition in the respiratory tract, but two other factors, surface area and surface activity, are likely involved as well ${ }^{16-18}$. For a given mass of particles, as the diameter of the particles is reduced, the number of particles increases exponentially and the surface-to-volume ratio increases linearly, as shown in figure 2.

Figure 2: Increase in particle number and surface area with decrease in size $e^{19}$

It is well established in the use of industrial catalysts that atoms in the core of a catalyst particle contribute little; surface area is the key factor in accelerating a chemical reaction. There is accumulating evidence that the toxicity of quartz is to some extent related to a catalytic effect that causes the generation of reactive oxygen species and thus is enhanced by particles of very high surface area ${ }^{20}$. This oxidant stress effect, a product both of surface area and surface reactivity, when combined with the alveolar deposition of sub-10 $\mu \mathrm{m}$ particles, makes quartz a very serious occupational health concern.

For nanoscale materials, a surprisingly large fraction of the atoms in a particle are on the surface, available for interaction with biological molecules, as shown in figure 3 . In the 
case of a $\mathrm{ZnS}$ quantum nanodot, 4 micrometers in diameter, roughly half of all the molecules in the particle are on the surface. For a single walled carbon nanotube or buckyball, every atom in the particle is on the surface.

Figure 3: Percentage of atoms on the surface of particles as a function of particle diameter $^{21,22}$

In numerous studies, poorly soluble low toxicity nanoscale particles have been shown to be more toxic than microscale materials of the same composition and mass ${ }^{17,23-28}$. There is significant evidence that in the nanoscale these materials are uncharacteristically toxic due in part to accelerated generation of free radicals, hydrogen peroxide and hydroxyl atoms, driven by high surface area ${ }^{20,22}$. While there are several proposed pathways leading to these reactive oxygen species, in the end they all ultimately result in damaged DNA, proteins, lipids and other biomolecules, inflammation and even cell death.

The work of Oberdörster and collaborators in this regard is widely referenced. As shown in figure 4, Oberdörster demonstrated that nanoscale $\mathrm{TiO} 2$ appeared to be much more inflammatory in lung than microscale $\mathrm{TiO} 2$ particles when compared on the basis of mass of material introduced into the lung ${ }^{20}$. However, when the data were plotted on the basis of surface area rather than mass, the inflammatory response was identical for both nanoand microscale particles ${ }^{17,23}$. Others have reported this surface area effect for various 
particles of low toxicity including metal oxides, polymers ${ }^{17}$, arbon black $^{29-32}$, and other carbonaceous nanoparticles $^{22}$

Figure 4: Relationship between mass (left) or surface area (right) and toxicity for $\mathrm{TiO} 2\left[{ }^{17,19}\right]$

However, for perspective, figure 6 shows that per unit surface area, quartz is much more toxic than $\mathrm{TiO} 2^{17,28}$. Similarly, nanoscale nickel and cobalt particles are much more toxic than $\mathrm{TiO} 2^{33}$. Thus, it is not surface area alone that determines the toxicity of all nanoparticles, but rather the product of surface area, surface reactivity, and elemental toxicity. This variability in surface reactivity even extends to the various crystalline forms of $\mathrm{TiO}^{14,15}$.

Indeed, even in the well-worn case of quartz there is a wide range of bioactivity in samples obtained from different parts of the earth or handled differently ${ }^{17}$ and much of the toxicity can be erased by prior treatment with aluminum ${ }^{19}$

Figure 5: Relative inflammatory potency of SiO2 compared to $\mathrm{TiO} 2$ and $\mathrm{BaSO} 4$ particles on an equal surface area basis ${ }^{34}$ 
It is important to note that not all researchers have been able to reproduce this surface area-dependent effect for a range of nanoscale particles ${ }^{33,35,36}$, and some of the aforementioned positive studies have been criticized on the way in which they derived and interpreted their data ${ }^{37}$. However, at this time, for nanomaterials of low solubility and low intrinsic toxicity, surface area as determined empirically is likely the best dose metric.

\section{Case Study: Environmental Ultrafines}

There is mounting evidence that exposure to environmental ultrafine ( nano) particles, particularly combustion derived nanoparticles (CDNP), contributes to community respiratory and cardiovascular morbidity and mortality ${ }^{38-40}$. Epidemiological and experimental studies have consistently indicated that exposure to these incidental nanoparticles predisposes compromised people to illness one or a few days postexposure $^{37,41-45}$. Originally attributed to larger particles, it is now likely that much of this observed health impact is due to ultrafine CDNP in air pollution ${ }^{1}$.

It is likely that the toxic potential of some engineered nanoparticles will parallel this effect of CDNP. For example it appears that pulmonary deposition of carbon nanotubes has some of the same adverse cardiovascular effects as CDNP. Indeed, it is now known that CDNP air pollution includes large numbers of multi-walled carbon nanotubes ${ }^{46,47}$. 


\section{Case Study: Carbon Nanotubes}

The special case of carbon nanotubes is illustrative of many of the difficulties in assessing the toxicity of novel nanostructures.

Carbon nanotubes come in two primary forms_-single walled nanotubes (SWCNT) and nested multiwalled nanotubes (MWCNT). They are being produced by the ton and incorporated into many commercial products including baseball bats, bicycles and other sporting equipment. Nanotubes range in diameter from about one nanometer (SWCNT) to dozens of nanometers (MWCNT) and can have lengths into the micrometer range.

Figure 6: Single and multi-walled carbon nanotubes

A large number of in vitro toxicity studies have been reported for carbon nanotubes, with most demonstrating unusual cytotoxicity to a range of target cells, as shown in table 2 . 


\begin{tabular}{|c|c|c|c|}
\hline Year & Author & Cell Line & Main findings \\
\hline 2003 & Shvedova & Human skin fibroblasts & Cell death, oxidative stress \\
\hline 2005 & Ding & $\begin{array}{l}\text { Human skin/lung } \\
\text { fibroblasts }\end{array}$ & $\begin{array}{l}\text { MWCNT induce does-dependent cytotoxicity, } \\
\text { induce genes indicative of a strong immune, stress } \\
\text { and inflammatory response }\end{array}$ \\
\hline 2005 & Jia & $\begin{array}{l}\text { Human lung } \\
\text { macrophages }\end{array}$ & $\begin{array}{l}\text { SWCNT more toxic than MWCNT10, both more } \\
\text { toxic than quartz }\end{array}$ \\
\hline 2005 & Murr & $\begin{array}{l}\text { Mouse lung } \\
\text { macrophages }\end{array}$ & $\begin{array}{l}\text { S/MWCNT "ropes" showed dose related } \\
\text { cytotoxicity, more toxic than asbestos }\end{array}$ \\
\hline 2005 & Fiorito & $\begin{array}{l}\text { Mouse \& Human } \\
\text { macrophages }\end{array}$ & $\begin{array}{l}\text { CNT were not well taken up by macrophages and } \\
\text { caused little toxicity, metals cause CNT toxicity }\end{array}$ \\
\hline 2006 & Kagan & $\begin{array}{l}\text { Human lung } \\
\text { macrophages }\end{array}$ & $\begin{array}{l}\text { Oxidative stress is related to iron contamination, } \\
\text { macrophages do not effectively engulf CNTs }\end{array}$ \\
\hline 2006 & Tian & Human fibroblasts & $\begin{array}{l}\text { Surface area predicts cytotoxicity, SWCNT more } \\
\text { toxic than MWCNT }\end{array}$ \\
\hline 2006 & Pluscamp & $\begin{array}{l}\text { Lung macrophage and } \\
\text { epithelial cells }\end{array}$ & $\begin{array}{l}\text { Little acute cytotoxicity of MWCNT, toxicity } \\
\text { related to metal contamination }\end{array}$ \\
\hline 2006 & Tian & Human fibroblast & $\begin{array}{l}\text { Surface area predicts cytotoxicity, SWCNT more } \\
\text { toxic than MWCNT or other carbon. Refined } \\
\text { SWCNT more toxic than unrefined SWCNT }\end{array}$ \\
\hline 2007 & Wick & Human mesothelioma & $\begin{array}{l}\text { Nanoropes more toxic than asbestos, dispersed } \\
\text { CNTs less toxic }\end{array}$ \\
\hline
\end{tabular}

Table 2: Selected in vitro studies of carbon nanotube cytotoxicity

In some of these in vitro studies, nanotubes appeared to be more toxic than quartz or asbestos, both of which induce lung inflammation, fibrosis and ultimately cancer. Several of the authors ascribed the observed toxicity to the metals contaminating impure carbon nanotubes $^{6,48-51}$.

If carbon nanotubes are instilled or aspirated into the lungs of rodents they induce signs of oxidative stress, much like the metal oxide nanoparticles discussed previously, and in 
most cases cause fibrosis and granuloma formation ${ }^{52}$. Depletion of vitamin E, a potent antioxidant, exacerbates the oxidative stress and profibrinic activity ${ }^{53}$. All of the published studies of this type are summarized in table 3.

However, these dosing methods are clearly non-physiological, it is quite possible that some of these pathologies, particularly the granulomas, are artifacts of the assay and will not occur in occupationally exposed individuals. A very recent publication from NIOSH supports this hypothesis, where they found no granulomas when they used extremely finely ground single walled carbon nanotubes rather than larger particles of agglomerated tubes $^{54}$.

\begin{tabular}{|c|c|c|c|c|c|}
\hline Year & Author & Species & Granuloma & Inflammation & Fibrosis \\
\hline 2001 & Huczko & G. pig & $\mathrm{NA}$ & - & $\mathrm{NA}$ \\
\hline 2004 & Warheit & Rat & + & $+/-$ & + \\
\hline 2004 & Lam & Rat & + & + & $\mathrm{NA}$ \\
\hline 2005 & Muller & Rat & + & + & + \\
\hline 2005 & Grubek - Jaworska & G. Pig & + & + & + \\
\hline 2005 & Shvedova & Mouse & + & + & + \\
\hline 2006 & Mangum & Rats & + & - & + \\
\hline 2006 & Carrero - Sanchez & Mice & + & + & NA \\
\hline 2007 & Shvedova & Mice & + & + & + \\
\hline 2008 & Mercer & Mice & - & + & + \\
\hline
\end{tabular}

Table 3: Summary of findings from all published carbon nanotube

instillation/aspiration pulmonary toxicology studies 
Mitchell recently published an inhalation study where mice were exposed to multi-walled carbon nanotubes $^{55}$. No evidence of lung inflammation, fibrosis or granuloma formation was detected, but the authors did find evidence of impairment of the animal's immune systems, a new and unique finding. The Mitchell study has been challenged due to a number of significant methodological problems, thus its validity is uncertain ${ }^{56} 32$.

In contrast, preliminary reports from NIOSH indicate that inhaled single and multiwalled carbon nanotubes cause rapid but transient inflammation and consistent diffuse lung fibrosis. In the SWCNT inhalation study, the fibrosis is reported to be four times as severe than was seen for the same doses via aspiration ${ }^{57,58}$. No mention of granulomas was made in this context.

Carbon nanotubes may also cause cancer, based on their morphology and biodurability. Carbon nanotubes can be viewed as rolled-up layers of graphite that forms a single tube about a nanometer in diameter (SWCNT) or a series of concentric nanotubes that can be a few or dozens of nanometers in diameter (MWCNTs). Carbon nanotubes can be thousands of nanometers in length, they have high tensile strength ${ }^{49}$ and relatively low solubility in biological systems ${ }^{1,59}$. They tend to cling together to make larger structures called nanoropes that are many nanometers or even micrometers in diameter.

These characteristics are all remarkably similar to a naturally occurring magnesium silicate nanotube, chrysotile asbestos, shown in figure $7^{59}$. 
Figure 7: Cross section of fibril of chrysotile asbestos showing lamellar structure and size very similar to $M W C N T s^{60,61}$

Inhaled chrysotile asbestos causes macrophage death, respiratory inflammation, fibrosis, lung cancer and probably mesothelioma, a cancer of the lining of the lungs and other $\operatorname{organs}^{62}$. However, these effects are not unique to the chemistry of chrysotile. Indeed, the amphibole forms of "asbestos", which are chemically unrelated to chrysotile and do not share the lamellar structure, also induce fibrosis and cancer. The occurrence of fibrous erionite (a form of zeolite) in the Cappadokia region of Turkey and elsewhere is associated with a highly elevated risk of mesothelioma ${ }^{63}$. Even man made fibers, such as some mineral fibers and refractory ceramic fibers, have the potential to induce these diseases $^{64}$.

Originally proposed by Stanton and Wrench in $1972^{63}$, it is now generally accepted that inhaled fibrous particles have the potential to cause fibrosis and cancer if they meet certain criteria of size, shape and biodurability:

- Particles must be small enough to be deposited in the alveoli

- Particles must have the right shape, including a high aspect ratio, a length of over $5 \mu \mathrm{m}$ or more and a sub-micrometer diameter.

- Particles must resist dissolution and clearance in the lungs 
As shown in table 4, widely divergent fiber chemistries cause the same toxic endpoints if they have the right size, shape and biodurability ${ }^{49}$.

It is evident that CNTs have the requisite size, strength and morphology to be suspect in this model. Very limited data are available on their biodurability. Muller ${ }^{63}$ showed that $80 \%$ of unground and $36 \%$ of ground MWCNTs were retained in lung tissue after 60 days, suggesting that MWCNTs may be adequately persistent to cause fibrosis and cancer.

\begin{tabular}{|l|l|c|c|c|}
\multicolumn{1}{c}{ Fiber } & \multicolumn{1}{c}{ Type } & \multicolumn{1}{c}{ Lung Half } \\
\multicolumn{1}{c}{ Life (Days) } & \multicolumn{1}{c|}{ Fibrosis } & Tumors \\
\hline MMVF34 & Stone Wool & 6 & - & - \\
\hline MMVF11 & Glass Wool & 9 & - & - \\
\hline MMVF10 & Glass Wool & 37 & - & - \\
\hline MMVF33 & 475 Glass & 49 & + & + - $^{\mathrm{a}}$ \\
\hline RCF1a & Refractory & 55 & + & + \\
\hline MMVF32 & E Glass & 79 & + & + \\
\hline Amosite & Asbestos & 418 & + & + \\
\hline Crocidolite & Asbestos & 817 & + & + \\
\hline & & \multicolumn{2}{c}{${ }^{a}$. Positive in hamsters but not rats } \\
\hline
\end{tabular}

Table 4: Correlation between lung biopersistence of long fibers and lung pathology $y^{32}$

Limited in vitro testing indicates that carbon nanotubes, like asbestos, can interact with DNA $^{65}$ and cause large scale chromosomal damage, but show no activity in the Ames point mutation assay ${ }^{66,67}$. Carbon nanotubes and asbestos interact with tissue to create reactive oxygen species ${ }^{32,68}$. However, no one has studied whole animals past 90 days to truly assess the carcinogenicity of inhaled carbon nanotubes. 
Surprisingly, carbon nanotubes deposited in the respiratory tract can induce toxic effects in other organ systems. A recent NIOSH report, described in more detail below, shows a range of cardiovascular toxicity due to inspired single walled carbon nanotubes ${ }^{58}$.

While some material safety data sheets have suggested that the exposure limit for carbon nanotubes should be based on the graphite standard (TLV $=5 \mathrm{mg} / \mathrm{m} 3$ for respirable dust), the instillation/aspiration studies indicate that this exposure level may be unsafe ${ }^{69}$. Some authors have suggested the use of the PEL for quartz, $0.1 \mu \mathrm{g} / \mathrm{m} 3$, as a better starting point $^{70}$

The hazard posed by any workplace chemical is a product of both the chemicals intrinsic toxicity and the potential for exposure. Few studies have assessed the exposure potential during the handling of carbon nanotubes. The most notable investigation found levels of up to $53 \mu \mathrm{g} / \mathrm{m} 3$ in an occupational setting where nanotubes were made and harvested ${ }^{71}$. Free fibers were rare; almost all of the carbon nanotubes measured were large aggregates. In this regard carbon nanotubes are very different from chrysotile asbestos, where handling of processed mineral fiber does release a large number of free nanofibers.

\section{Case Study: Quantum Dots}

Quantum nanodots are single-digit sized particles made up of semiconductor metals that demonstrate the amazing feature of changing fluorescence wavelength based on their size. Quantum nanodots present an interesting case in that many of these are intrinsically cytotoxic due to their metal content (e.g. $\mathrm{Cd}, \mathrm{Pb}, \mathrm{Se}){ }^{72}$. Uncoated nanodots are quite 
cytotoxic, and it is possible that their toxicity exceeds the sum of the toxicity of the constituent metals. For example, $\mathrm{Cho}^{73}$ showed that cytotoxicity of a variety of coated nanodots in a breast cancer cell line did not fully correlate with the generation of $\mathrm{Cd} 2+$ ions. Instead, the quantum nanodots were consistently more toxic that predicted by their release of $\mathrm{Cd} 2+$ ion (figure 8 ). In this study quantum dot net toxicity appears to be a result of both intrinsic metal ion toxicity and induction of oxidative stress by the surface of the intact nanoparticle, the latter effect the same as seen for $\mathrm{TiO} 2$, carbon nanotubes and other nanoparticles.

Fortunately, quantum dots can be coated with various polymers and biologically compatible molecules that shield the semiconducting core from dissolving or interacting with tissue, which greatly reduces their toxicity ${ }^{72}$.

Figure 8: Plot showing reduction in cell viability as a function the propensity of $C d 2+$ ions to plate off of CdSe quantum nanodots with different protective coatings. The doted line represents the dose/toxicity relationship for pure $\mathrm{Cd} 2+$ ions. The nanodots are uniformly more toxic than would be predicted by their release of $C d 2+$ ions $^{74,75}$.

\section{Distribution Across Anatomical Barriers and Systemic Effects}

Exposure to nanoscale particles can occur via any of the usual routes of exposure, that is, inhalation, ingestion and skin contact. As with other chemical occupational stressors, 
each of these routes of exposure must be evaluated to determine the extent of deposition, absorption, distribution, excretion and toxicity.

Insoluble nanoparticles may be more mobile across anatomical barriers that microscale or larger insoluble particles of the same chemistry. Also, nanoparticles may exert systemic toxic effects that may not depend on translocation of the particles.

Digestive and Respiratory Tracts: It has been known for many years that some intact nanoparticles cross the digestive tract and respiratory tract and appear in the body ${ }^{76}$.

Although subject to ongoing controversy related to methodological limitations ${ }^{76,77}$, inhaled nanoparticles have some ability to cross through or around the cells in the lungs, enter the interstitial space and are distributed systemically ${ }^{76}$. This clearly happens, but the extent of this process and significance remains in question. Early studies that suggested very rapid translocation of nanoparticles out of lung ${ }^{53,78-80}$ were likely flawed, more recent work has suggested a slow migration of a small percentage of particles out of the lung that is exacerbated by lung inflammation ${ }^{81}$.

Skin: Many sunscreens contain micro or nanoscale zinc or titanium oxide particles. In general, studies suggest that intact skin is a pretty good barrier to these particles ${ }^{82}$. Under some circumstances, sub micrometer particles can penetrate the skin, at least as far as the living tissue underlying the stratum corneum ${ }^{82,83}$. It is not clear that these particles travel as far as the systemic circulation or if they are toxicologically significant. This route of 
exposure is likely to be of greater importance for damaged skin or concomitant exposure to solvents and nanoparticles ${ }^{83}$.

Figure 9: Image showing $500 \mathrm{~nm}$ fluorescent beads penetrating to the living layers of the skin, but 4 m beads stopped on the surface of the $\operatorname{skin}^{84}$.

Brain: Although not completely unprecedented ${ }^{85}$, it was certainly remarkable when it was demonstrated that carbon nanoparticles ${ }^{86}$ and manganese oxide nanoparticles ${ }^{87,88}$ deposited in the olfactory mucosa in rodents translocated up the olfactory neuron axons into the brain and in some studies triggered inflammation in neural tissue. This is intriguing in light of the lung deposition model proposed by the International Council on Radiation Protection that shows nanoparticles less than $10 \mathrm{~nm}$ in aerodynamic diameter will preferentially deposit in the head airways region rather than the alveolar space ${ }^{89-91}$. There is also evidence that some, but not all, nanoparticles can penetrate the blood-brain barrier and gain access to the brain via the bloodstream ${ }^{91,92}$.

The importance of these brain translocation mechanisms in humans is unknown. Humans have far less olfactory mucosa than rodents. For perspective, welders have been inhaling adventitious metal oxide nanoparticles for decades with relatively little obvious adverse neurological effect for metals other than manganese. 
Placenta: The placenta seems to present a more formidable barrier to nanoparticle translocation $^{93}$, although at least one report suggested translocation into the fetus ${ }^{91,94}$.

\section{Systemic Toxicity}

In general, the consequence of translocated nanoparticles has not been established. As might be expected, nanoparticles in the blood stream are sometimes accumulated in the liver and lymph nodes, as shown for quantum dots in a mouse in figure $10^{94}$.

Figure 10: Accumulation of injected quantum nanodots in the lymph nodes, bone marrow and liver of a mouse ${ }^{68}$.

Li of NIOSH studied the cardiovascular toxicity of carbon nanotubes aspirated into the lungs of rats genetically modified to rapidly develop atherosclerosis ${ }^{42}$. This pulmonary exposure resulted in cardiovascular toxicity, including accelerated atherosclerosis, oxidative stress in aorta and heart tissue and damage to aortic mitochondrial DNA. The exposure level used in this study was intended to approximate the potential human exposure at the PEL for respirable graphite.

It is not known if this cardiovascular toxicity was due to translocated nanotubes interacting directly with aortic and heart tissue or some type of secondary response, due to the observed inflammation of lung tissue. Recall that inhalation of environmental ultrafine combustion particulate matter also induces cardiovascular toxicity ${ }^{32}$. 
As yet unpublished work by Castranova at NIOSH finds that $\mathrm{TiO} 2$ particles instilled into the lungs of rodents causes dysfunction of the microvascular system ${ }^{32}$. Treated animals showed blunting and even reversal of the response to dilators that was dose dependent, more severe for nanoparticles than for microparticles and appeared within 1 day of dosing. Confocal microscopy demonstrated rapid accumulation of polymorphonuclear leukocytes all along the microvascular walls. This is likely a systemic effect rather than due to translocated particles based on the rapidity of response.

NIOSH has also presented preliminary data which suggest that pulmonary exposure to MWCNTs and TiO2 nanowires may degrade the integrity of the blood brain barrier and cause brain damage, primarily in the olfactory bulb, hippocampus and frontal cortex ${ }^{95}$. This was not due to translocation up the olfactory nerve. In the case of the MWCNT this effect was seen with doses in the range of what a person would be exposed to at the PEL for graphite.

Very little work has been done to assess the potential reproductive toxicity of engineered nanoparticles. One brief report indicates that gold nanoparticles may have a negative impact on sperm function in vitro ${ }^{96}$. A recent study found that pulmonary deposition of carbon black had negative impact on the reproductive system of male mice ${ }^{93,97}$. Older references suggests that C60 may have fetotoxic potential ${ }^{98}$. These studies are two few and incomplete to allow any conclusions regarding the reproductive toxicity of nanoparticles. 


\section{Goals of an Occupational Medicine Program}

Broadly construed, occupational medicine programs attempt to limit the health effects of chemical and physical stressors in the workplace. With respect to chemically induced disease, the goals of an occupational medicine program are, in order of preference:

\section{Prevent occupational diseases from occurring}

\section{Quickly detect occupational diseases that do occur}

\section{Intervene to cure occupational diseases}

\section{Goal 1:Prevent Occupational Disease}

This goal, preventing occupational illness entirely, is the loftiest ambition of an occupational medicine program. Traditionally, the paradigm for achieving this goal relies on four key program elements:

Workplace Exposure Monitoring-Exposure to chemical agents is assessed either by environmental monitoring (e.g., air monitoring, dermal exposure assessment) or biological monitoring (e.g., blood analysis, urinalysis, lung counting). The results of these assays are compared to established limits as an index of the risk.

Establish Workplace Controls-Controls are established to reduce employee exposure to occupational stressors. Controls may include engineered controls 
(e.g., ventilation, filtration, enclosure), administrative controls (e.g., safe work practices, training) and personal protective equipment (e.g., gloves, respirators, goggles).

Medical Pre-Screening for People at Elevated Risk-Prior to exposure to an occupational stressor, the working population is screened for conditions that may put them at elevated risk of occupational disease. At-risk employees may be offered alternative assignments or enhanced protection to reduce their chances of becoming ill.

Medical Surveillance- In this context, medical surveillance is narrowly defined to describe a process of looking for health trends in the worker community that might warrant further action. This is distinct from "medical monitoring", which is the key element of goal two and has a clinical focus ${ }^{98}$. Note that in practice many people use the terms medical monitoring and medical surveillance interchangeably, but in fact they are conceptually distinct. Some OSHA standards have "medical surveillance" provisions, but these are better described as "medical monitoring". 10

This paradigm requires several elements to be in place:

- Exposure monitoring methods are available and affordable

- A standard exists to which measured exposures can be compared

- Control methods applicable to larger particles are effective for nanoparticles 
- The target organ(s) and health effects are known and can be screened

- The impact of pre-existing conditions on risk are known

- Alternatives are available for employees found to be at increased risk of disease due to preexisting conditions

For most nanoscale particulate matter, there are no accepted exposure monitoring methods, no exposure standards, the effectiveness of traditional control methods is only now being elucidated, the target organs are not always obvious and the impact of preexisting conditions on risk is not clear. This makes it very difficult to establish an evidence-based program to prevent the manifestation of occupational disease related to nanoparticles.

\section{Exposure Monitoring}

As of December 2007, there are almost no published consensus methods to measure exposure to nanoscale materials or exposure standards to compare to the results. NIOSH has proposed a draft an exposure limit of $0.1 \mathrm{mg} / \mathrm{m} 3$ for nanoscale $\mathrm{TiO} 2$, which stands alone as a widely recognized exposure standard specific for engineered nanostructured materials in the U.S. ${ }^{99}$.

It is a simple matter to buy handheld condensation nuclei counters that can enumerate airborne nanoparticles down to $10 \mathrm{~nm}$ in diameter, but it is difficult even to obtain relative measurements with these instruments due to the extremely high and variable background level of natural and anthropogenic ultrafine particles. In laboratory settings, 
the signal of interest is likely to be a small fraction of the background noise. Also these instruments are not size or chemistry specific. Even with these limitations these instruments have been used successfully in factory settings as part of research efforts ${ }^{100}$.

Size-selective real time aerosol monitors for measuring nanoscale particulate matter, such as mobility particle spectrometers, are available but this equipment is very expensive, large, and requires special training to operate. A number of researchers have reported successful deployment of this type of instrument in labs and factories ${ }^{101-103}$. Like the simpler condensation nuclei counters, these instruments are not able to distinguish engineered nanoparticles from background ultrafines.

Particles can be collected on filters or other media with subsequent analysis by electron microscopy. This allows for speciation and sizing of nanoparticles, but at huge cost in terms of time and expense and requires expertise that is of very limited availability right now.

NIOSH has reported the results of an investigation where they built a clean room around a carbon nanotube source, thus removing the confounding background particles. They also avoided the problem with nanoparticle measurement techniques by measuring the level of airborne residual catalyst metals and back-calculating the exposure to carbon nanotubes. Interestingly, the authors found only relatively low levels of carbon nanotubes in their air samples and attributed this result to the extensive agglomeration of the newly synthesized tubes into micro- and macro clumps that did not readily become airborne. 
This level of effort is feasible for a funded research study, but not for routine exposure monitoring, especially in research labs where the work changes all the time.

The vast majority of industrial hygiene exposure limits for particulate matter are specified on a mass basis. Thus OSHA limits exposure to lead to $50 \mu \mathrm{g} / \mathrm{m} 3$ of air averaged over an 8-hour day. The exposure limit for some fibrous materials is based on particle count. However, there is no generally accepted sampling method to evaluate particle surface area, likely the most relevant exposure metric for many nanoscale particles. Some research in this area has been done ${ }^{104}$ and at least one vendor offers an instrument purported to measure surface area directly, but this suffers from the same interference from ambient ultrafines and lack of chemical specificity as the simple particle counting instruments. This instrument is primarily a research tool at this time.

Where existing exposure limits based on chemistry are available, great caution must be exercised before applying them to nanoparticles. For example, the toxicity of uncoated CdSe quantum nanodots may be a function both of the intrinsic metal ion toxicity and the catalytic promotion of oxidative stress that is a property of the intact nanoparticle. Existing Cd exposure limits do not account for these dual pathways to toxicity. Similarly, use of the graphite exposure limit for structurally related carbon nanotubes may lead to disease, as the morphology of the nanotube induces additional toxicological mechanisms that are not accounted for in the exposure standard. 


\section{Medical Pre-Screening}

There is currently no technical basis for recommending medical prescreening criteria for most nanoparticle exposed workers.

\section{$\underline{\text { Exposure Control }}$}

Until quite recently, it was not clear that the usual triumvirate of engineered, administrative and personal protective controls was adequate to control exposure to nanoparticles.

In 1991 it was proposed that nanoparticles smaller than about $10 \mathrm{~nm}$ might not be effectively captured by mechanical air filters due to a "thermal rebound" effect ${ }^{105}$. The authors calculated that at some size the nanoparticles would rebound from the filter matrix due to their propensity to diffuse and thus not be captured, much in the way that individual vapor or gas molecules pass unchecked through a filter. In 2004 a study was published that purported to demonstrate this effect for very small nanoparticles ${ }^{106}$. Other authors reported similar findings ${ }^{107}$. About this time it was also reported that N95 respirator filters, especially those that rely on electrostatic charge effects for particle deposition, might not perform quite at their stated efficiency for nanoparticles ${ }^{108-113}$.

Overwhelming data are now available from numerous investigators showing filters work as expected for particles as small as 2 nanometers ${ }^{109,110,114,115}$.The earlier negative reports suffered from methodological problems that resulted in erroneous conclusions ${ }^{110}$. 
Of course, at some size, filtration efficiency must drop off, as air and vapor molecules are not captured in a particulate filter. Data from Kim suggest that thermal rebound does appear at about $2 \mathrm{~nm}$, just about the diameter of a buckyball ${ }^{108}$.

Discussion continues regarding the permeability of gloves and other elastomeric materials to nanoparticles. However, limited studies to date indicate that latex and nitrile rubber gloves form a reliable barrier to nanoparticles under test conditions ${ }^{110}$.

Figure 11: Penetration of nanoparticles through a low efficiency filter as a function of size, showing that particles below $2 \mathrm{~nm}$ may not be captured as predicted by filtration theory ${ }^{100,116}$

Despite some suggestions to the contrary, local exhaust ventilation will function for engineered nanoscale particles exactly as it has all along for incidentally produced nanoparticles ${ }^{100}$.

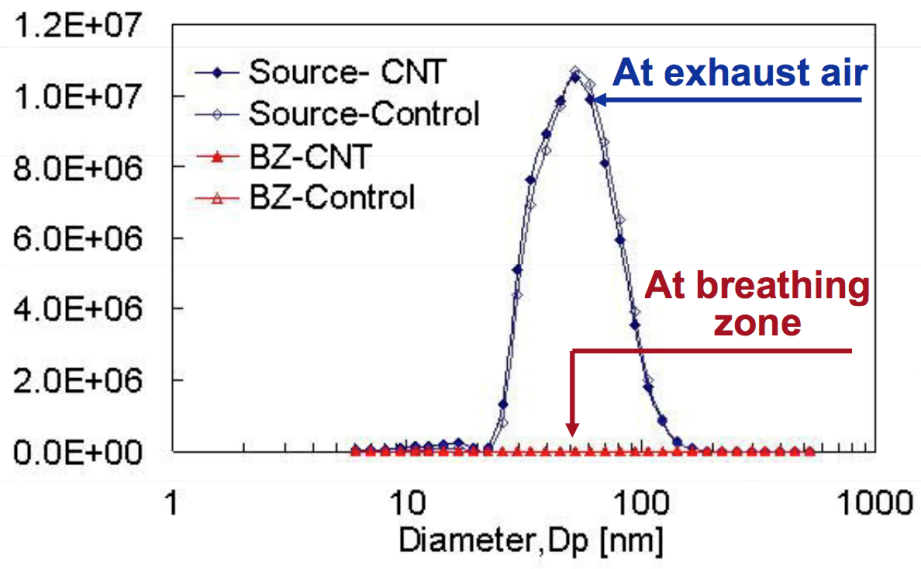


Figure 12: Demonstration of the effectiveness of a fume hood at preventing exposure to carbon nanotubes ${ }^{17-119}$.

In summary, the management of exposure to nanoparticles can in most cases be achieved using familiar engineered, administrative and personal protective control measures.

\section{Medical Surveillance}

NIOSH, the NNI and Nasterlick from BASF have recommended the establishment of worker medical surveillance programs to monitor for the emergence of sentinel cases of new disease ${ }^{98,117}$. At this time it is unlikely that most employers have the capability or will to establish a meaningful sentinel event medical surveillance program, so as a practical matter, medical surveillance is not likely to figure prominently in occupational medicine programs for nanoparticles for the near term.

\section{Goal 2: Detect Occupational Disease Quickly}

The second goal of occupational health surveillance is to detect subclinical signs of illness in a worker population, with an eye toward quick intervention to prevent development of overt disease. This process is most commonly called "medical monitoring" in the United States ${ }^{119}$ and is mandated by the Occupational Safety and Health Administration for some chemical agents such as asbestos, lead and benzene (although most laboratory work is exempted from these requirements).

The criteria for establishing a medical monitoring program include ${ }^{117,119}$ : 
- Understanding who is being exposed

- Knowledge of the target organ(s) and specific health effects

- Availability of reliable and safe medical tests

- Action criteria to compare to test results

- Availability of interventions to arrest or reverse disease

Medical monitoring often includes diagnostic studies to identify perturbations that disclose the preliminary stages of occupational disease. Thus for asbestos, which causes pulmonary fibrosis, lung cancer and mesothelioma, OSHA mandates that the medical evaluation include a chest $\mathrm{x}$-ray and pulmonary function testing. Whereas preclinical detection of mesothelioma is largely irrelevant (it is essentially $100 \%$ fatal), the discovery of subclinical disease may result in limiting further asbestos exposure that can reduce the progression of fibrosis. Early-stage lung cancer may be treatable via surgery and other interventions.

For most nanomaterials, it is unclear what diagnostic studies should be included in a medical monitoring program ${ }^{119}$. While many suggestions have been, including measurement of heart rate variability, proinflammatory cytokines, lung CT studies, liver enzyme tests, etc., none of these rise to the level of validation normally required for inclusion in a targeted medical monitoring $\operatorname{program}^{119}$. The sensitivity, specificity and risk/benefit ratio of such testing is unknown with respect to most nanoparticles. 
It is also not always clear who should be included in a monitoring program, as the usual inclusion criteria incorporate the results of exposure monitoring that are not likely to be available for nanoparticles.

Nasterlack and colleagues at BASF in Germany published an opinion paper that argues that routine medical monitoring of workers exposed to nanoparticles is not warranted or feasible at this time, and effort should instead be expended on control measures to prevent exposure $^{117}$.

NIOSH has recently published a draft guideline that proposes "Insufficient scientific and medical evidence now exists to recommend the specific medical screening of workers potentially exposed to engineered nanoparticles".

The feasibility of medical monitoring is likely to evolve as the findings of more whole animal toxicological studies become available. For example, if new inhalation studies confirms the relationship between carbon nanotubes inhalation and lung fibrosis and granuloma formation, it will be reasonable to formulate specific guidelines for medical surveillance of workers exposed to these materials.

\section{Goal 3: Treatment of Disease}

If all else fails and occupational disease is manifested, the third goal of occupational medicine it to heal those injured by their experience at work. This might be affected by 
removing the injured individual from further exposure via transfer, or via some form of treatment.

Medical removal is not always effective at limiting the progression of disease and raises real concerns for both the employer and employee. This inevitably leads to ethical and practical quandaries. Specifically, is it justifiable to remove a worker from his or her job based on the results of uncertain tests, without knowing if this intervention will make any difference in disease outcome?

\section{Conclusion}

As the discovery and commercialization of nanoscale materials expands, occupational health professionals such as physicians and industrial hygienists will be forced to develop hazard assessment, exposure control and health monitoring strategies without the usual panoply of tools.

This quandary is not that unusual in a research setting such as a university or pharmaceutical company, where the creation of novel materials is the stock-in-trade. However the widespread use of materials of uncertain hazard in diverse industries, big and small, is unusual and may pose an unacceptable risk that will not be recognized until cases of disease start appearing in number. 
The emerging nanotechnology revolution is another grand step in the industrial revolution that has been underway for over 200 years. As with prior steps in the revolution there will likely be anticipated and unanticipated consequences, both good and bad, of new technologies. The goal should be to anticipate and mitigate adverse consequences before people are injured or the environment is contaminated. If history is any indication, this will be a very difficult task.

Strategies to manage the poorly defined risk of nanoparticulate matter are beginning to appear from various government and consensus standard setting organizations in the United States and Europe. The companion manuscript to this paper presents the hazard assessment and control recommendations for research laboratories developed by the five Department of Energy Nanoscale Science Research Centers

Acknowledgement: This work was supported by the Director, Office of Science, Office of Basic Energy Sciences, Materials Sciences and Engineering Division, of the U.S. Department of Energy under Contract No. DE-AC02-05CH11231 
References:

1. $\quad$ L. E. Murr; K. F. Soto, Journal of Materials Science 2004, 39, (15), 4941-4947.

2. ETCGroup, Occasional Paper Series 2003, 7, (1), 20.

3. P. Wick; P. Manser; L. G. Limbach; U. Dettlaff-Weglikowsk; F. Krumeich; S. Roth; W. J. Stark;

A. Bruinink, Toxicology Letters 2007, 168, (2), 121-131.

4. L. Z. Wang, Materials Today 2004, 7, 7.

5. V. E. Kagan; Y. Y. Tyurina; V. A. Tyurin; N. V. Kondura; A. I. Potapovich; A. N. Osipov; E. R. Kisin; R. Schwegler-Berry; V. Mercer; V. Castranova; A. A. Shvdova, Toxicology Letters 2005, 165, (1), 13.

6. D. B. Warheit; B. R. Laurence; K. L. Reed; D. H. Roach; G. A. M. Reynolds; T. R. Webb, Toxicological Sciences 2004, 77, (1), 117-125.

7. J. M. Wörle-Knirsch; K. Pulskamp; H. F. Krug, Nano Letters 2006, 6, (6), 1261-1268.

8. $\quad$ L. S. Levy, Indoor and Built Environment 1995, 4, (5), 9.

9. ILSI, Inhalation toxicology 2000, 12, (1-2), 17.

10. NIOSH, in: November 22, 2005 ed.; N. I. f. O. S. a. Health, (Ed.) 2005.

11. E. Bermudex; J. Mangum; B. Wong; A. Bahman; P. Hext; Warheit, Toxicological sciences 2004, $77,11$.

12. C. M. Sayes; K. L. Reed; D. B. Warheit, Toxicol Sci 2007, 97, (1), 18.

13. C. M. Sayes; A. Marchione; K. Reed; D. Warheit, Nano Letters 2007, 7, (8), 8.

14. K. Donaldson; P. Borm, Annals of Occupatonal Hygiene 1998, 42, (5), 8.

15. C. Albrecht; A. M. Knaapen; A. Becker; D. Höhr; P. Haberzettl; F. J. van Schooten; P. J. A.

Borm; R. Schins, Respiratory Research 2005, 6, (129).

16. D. B. Warheit, Toxicological sciences 2007, 95, (1), 11.

17. R. Duffin; L. Tran; D. Brown; V. Stone; K. Donaldson, Inhalation Toxicology 2007, 19, (10), 849-

856. 
18. B. Railsback, in: teaching materials, Basic Geology, U. o. G. Department of Geology, 2002,

"Increase in particle number and surface area with decrease in particle size", http://www.gly.uga.edu/railsback/1121WeatheringArea.jpeg

19. A. D. Maynard, Annals of Occupational Hygiene 2007, 51, (1), 12.

20. G. Oberdörster; E. Oberdörster; J. Oberdörster, Environmental Health Perspectives 2005, 113, (7), 823.

21. Q. Zhang; Y. Kusaka; X. Zhu; K. Sato; Y. Mo; T. Kluz; K. Donaldson, Journal of Occupational Health 2003, 45, (1), 8 .

22. G. Oberdörster, Philosophical transactions: Mathematical, Physical and Engineering Sciences 2000, 358, (1175), 22.

23. D. M. Brown; M. R. Wilson; W. MacNee; V. Stone; K. Donaldson, Toxicology and applied Pharmacology 2001, 175, 9.

24. V. Stone; M. Tuinman; J. Vamvakopoulos; J. Shaw; D. Brown; S. Petterson; Faux; S. P.; W.

Borm; W. Macnee; F. Michaelangeli; K. Donaldson, Eruopean Respiratory Journal 2000, $15,7$.

25. X. Y. Li; P. Gilmour; K. Donaldson; W. MAcNee, Environmental health prespectives 1997, 105, (S5), 3 .

26. K. Donaldson; V. Stone; D. M. Gilmour; M. Brown; W. MacNee, Philosophical Transactions: Mathematical, physical and engineering sciences 2000, 358, (1175), 9.

27. C. M. Sayes; A. M. Gobin; K. D. Ausman; J. Mendez; J. L. Wst; V. L. Colvin, Biomaterials 2005, 26, (36), 9.

28. Q. Zhang; Y. Kusaka; K. Sato; K. Makakuku; N. Kohyama; K. Donaldson, 53 1998, 6, 16.

29. T. Stoeger; C. Reinhard; S. Takenaka; A. Schroeppel; E. Karg; B. Ritter; J. Heyder; H. Schulz, Environmental health perspectives 2006, 114, (3), 6.

30. C. Monteiller; L. Tran; W. MacNee; S. Faux; A. Jones; B. Miller; K. Donaldson, Occup Environ Med 2007, 64, (9), 7.

31. A. Maynard; E. Kuempel, Journal of Nanoparticle reseasrch 2005, 7, 29.

32. V. Castranova, in: Nanotechnology Update for IHs: Toxicology and exposure assessment, A. I. H. Association, (Ed.) American Industrial Hygiene Association: 2008. 
33. D. Warheit; T. Webb; S. Frerichs; C. Sayes, 2007.

34. $\quad$ K. Soto; K. M. Garza; L. E. Murr, Acta Biomateriala 2007, 3, (3), 351-358.

35. D. Warheit; T. Webb; C. M. Sayes; V. L. Colvin; K. L. Reed, Toxicological sciences 2006, 91, (1), 10

36. K. Wittmaak, Environmental health perspectives 2007, 115, (2), 8.

37. K. Donaldson; L. Tran; L. A. Jimenez; R. Duffin; D. E. Newby; N. Mills; W. MacNee; V. Stone, Particle and Fibre Toxicology 2005, 2, (10), 1743-8977.

38. D. W. Dockery; C. A. Pope; X. Xu; J. Spengler; J. WAre; M. E. Fay; B. G. Ferris; F. E. Speizer, New England Journal of Medicine 1993, 329, 7.

39. S. v. Klot; A. Peters; P. Aalto; T. Bellander; N. B. D. D'Ippoliti; R. Elosua; A. Hörmann; M.

Kulmala; T. Lanki; H. Löwel; J. Pekkanen; S. Picciotto; J. Sunyer; F. Forastiere, Circulation 2005, $112,7$.

40. R. Rückerl; R. Phillips; A. Schneider; M. Frapmton; J. Cyrys; G. Oberdörster; H. E. Wichmann;

A. Peters, Particle and Fibre Toxicology 2007, 4, (1), 14.

41. G. Oberdörster; J. ZFinkelstein; J. Ferin; R. Gelein; C. Johnson; J. Godleski; L.-Y. Change; J. D. Crapo, Chest 1996, 109, 2.

42. A. Nemmar; M. F. Hoylaerts; P. Hoet; B. Nemery, Toxicology letters 2004, 149, 11.

43. P. Penttinen; K. L. Timonen; P. Tiittanen; A. Mirme; J. Ruuskanen; J. Pekkanen, European REspiratory Journal 2001, 17, 8.

44. A. Peters; H. E. Wichmann; T. Tuch; J. Heinrich; J. Heyder, American Journal of Respiratory

Critical Care Medicine 1997, 155, 8.

45. R. Duffin; N. Mills; K. Donaldson, Yonsei Medical Journal 2007, 48, (4), 12.

46. K. Pulskamp; S. Diabaté; H. F. Krug, Toxicology Letters 2007, 168, (1), 58-74.

47. V. E. Kagan; Y. Y. Tyurina; V. A. Tyurin; N. V. Konduru; A. I. Potapovich; A. N. Osipov; E. R. Kisin; D. Schwegler-Berry; R. Mercer; V. Castranova; A. A. Shvedova, Toxicology Letters 2006, 165, (1), 88-100.

48. J. B. Mangum; E. A. Turpin; A. Antao-Menezes; M. F. Cesta; E. Bermudez; J. C. Bonner, Particle \& Fibre Toxicology 2006, 3, (15). 
49. J. Muller; F. Huaux; N. Moreau; P. Misson; J.-F. Heilier; M. Delos; M. Arras; A. Fonseca; J. B. Nagy; D. Lison, Toxicology and Applied Pharmacology 2005, 207, (3), 221-231.

50. A. A. Shvedova; E. R. Kisin; R. Mercer; A. R. Murray; V. J. Johnson; A. I. Potapovich; Y. Y. Tyurina; O. Gorelik; S. Arepalli; D. Schwegler-Berry; A. F. Hubbs; J. Antonini; D. E. Evans; B.-K. Ku; D. Ramsey; A. Maynard; V. E. Kagan; V. Castranova; P. Baron, American Journal of Physiology - Lung Cellular and Molecular Physiology 2005, 289, 698-708.

51. K. Donaldson; R. Aitken; L. Tran; V. Stone; R. Duffin; G. Forrest; A. Alexander, Toxicological Sciences 2006, 92, (1), 5-22.

52. A. A. Shvedova; E. R. Kisin; A. R. Murray; O. Gorelik; S. Arepalli; V. Castranova; S.-H. Young;

F. Gao; Y. Y. Tyurina; T. D. Oury; V. E. Kagan, Toxicology and Applied Pharmacology 2007, 221, (3), 339-348.

53. R. Mercer; J. Scabilloni; L. Wang; E. Kisin; A. Murray; S.-B. D; A. Shvedova; V. Castranova, American Journal of LungCell Molecular Physiology 2008, 294, (1), 11.

54. L. A. Mitchell; J. Gao; R. Vander Wall; A. Gigliotti; S. W. Burchiel; J. D. McDonald, Toxicological sciences 2007, 100, (1), 12.

55. D. Lison; J. Muller, Toxicological Sciences 2008, 101, (1), 2.

56. J. McDonald; L. Mitchell, Toxicological Sciences 2007, 101, (1), 2.

57. C. Schönenberger; L. Forró, Physicsworld 2000, 13, (June), 37.

58. O. L. Min-Feng Yu, Mark Dyer, Katerina Moloni, Thomas Kelly, Rodney Ruoff, Science 2000, 287,4 .

59. K. Yada, Acta Crystallographica Section A 1971, 27, (6), 5.

60. J. A. Merchant, Environmental Health Perspectives 1990, 88, 7.

61. I. J. Selikoff, Environmental Health Perspectives 1990, 88, 8.

62. S. H. Constantopoulos, Regulatory Toxicology and Pharmacology 2007.

63. T. W. Hesterberg; G. Chase; C. Axten; W. C. Miller; R. P. Musselman; O. Kamstrup; J. Hadley;

C. Morscheidt; D. B. Bernstein; P. Thevanaz, Toxicology and Applied Pharamcology 1998, $151,14$.

64. M. F. Stanton; C. Wrench, Journal of the National Cancer Institute 1972, 48, 24. 
65. E. R. Kisin; A. R. Murray; M. J. Keane; X. C. Shi; D. Schwegler-Berry; O. Gorelik; S. Arepalli;

V. Castranova; W. E. Wallace; V. E. Kagan; A. Shvedova, A., Toxicology and Encironmental Health 2007, $70,(24), 9$.

66. H. H. Nelson; K. T. Kelsey, Oncogene 2002, 21, (48), 7284-7288.

67. T. Ollikainen; K. Linnainmaa; V. L. Kinnula, Environ. Mol. Mutagen. 1999, 33, 153-160.

68. Z. Li; T. Hulderman; R. Salmen; R. Chapman; S. S. Leonard; S.-H. Young; A. Shvedova; M. I.

Luster; P. P. Simeonova, Environmental Health Perspectives 2007, 115, (3), 377.

69. C.-w. Lam; J. T. James; R. McCluskey; S. Arepalli; R. L. Hunter, Critical Reviews in Toxicology 2006, 36, (3), 189-217.

70. A. D. Maynard; P. A. Baron; M. Foley; A. A. Shvedova; E. R. Kisin; V. Castranova, Journal of Toxicology and Environmental Health, A 2004, 67, (1), 87-107.

71. A. M. Derfus; W. C. W. Chan; S. Bhatia, Nano Letters 2004, 4, (1), 8.

72. S. J. Cho; D. Maysinger; M. Jain; B. Röder; S. Hackbarth; F. M. Winnik, Langmuir 2007, 23, (4), 1974-1980.

73. R. Hardman, Environmental Health Perspectives 2006, 114, (2), 165-172.

74. J. P. Berry; B. Arnoux; G. STanislas; P. Galle; J. Chretien, Biomedicine 1977, 29, (9-10), 4.

75. P. Jani; G. Halbert; J. Langridge; A. T. Florence, Journal of Pharm Pharmacol 1990, 42, (12), 6.

76. A. Nemmar; P. H. M. Hoet; D. Vanquickenborne; M. Dinsdale; M. F. Thomeer; H. Hoylaerts; L.

Vanbilloen; L. Mortelmans; B. Nemery, Circulation 2002, 105, 411-414.

77. S. Taeenaka; E. Karg; C. Roth; H. Shultz; A. Ziesenis; U. Heinzmann; P. Schramel, Environmental health perspectives 2001, 109, (4), 5.

78. W. G. Kreyling; M. Semmler; F. Erbe; P. Mayer; S. Takenaka, Journal of Toxicology and Environmental Health, A 2002, 65, (20), 1513-1530.

79. M. Semmler-Behnke; S. Takenaka; S. Fertsch; A. Wenk; J. Seitz; P. Mayer, 2007, 115, (5), 6.

80. J. Chen; M. Tan; A. Nemmar; W. Song; M. Dong; G. Zhang; Y. Li, Toxicology 2006, 222, (3), 195-201.

81. J. Ladermann; H.-J. Weigmann; C. Rickmeyer; H. Barthalmes; H. Schaefer; G. Muller; W. Sterry, Skin, Pharamcology and Applied Sking Physiology 1999, 12, (5), 10. 
82. J. P. Ryman-Rasmussen; J. E. Riviere; N. A. Monteiro-Reviere, Toxicological Sciences 2006, 91, (1), 7 .

83. S. S. Tinkle; J. M. Antonini; B. A. Rich; J. R. Roberts; R. Salmen; K. DePree; E. J. Adkins, Environmental Health Perspectives 2003, 111, (9), 1202-1208.

84. H. A. Howe; D. Bodian, Proc Soc Exp Biol med 1940, 43, 4.

85. G. Oberdörster; Z. Sharp; W. Kreyling; C. Cox; V. Atudorei; A. Elder; R. Gelein, Inhalation

Toxicology 2004, 16, (7), 437-445.

86. A. Elder; R. Gelein; V. Silva; T. Feikert; L. Opanashuk; J. Carter; R. Potter; A. Maynard; Y. Ito; J. Finkelstein; G. Oberdörster, Environmental Health Perspectives 2006, 114, (8), 1172-1178.

87. I. C. o. R. Protection, Annals of the ICRP 1995, 24, (1-3).

88. B. Asgharian; O. Price, Inhalation toxicology 2007, 19, (13), 10.

89. K. K. Jain, Neurodegenerative Diseases 2007, 4, (4), 5.

90. $\quad$ P. Lockman; R. Mumper; M. Khan; D. Allen, Drug Dev Ind Pharm 2002, 28, (1), 13.

91. E. Sadauskas; H. Wallin; M. Stoltenberg; U. Vogel; P. Doering; A. Larsen; G. Danscher, Prticle and fiber toxicology 2007, 4 .

92. J. Challier; M. Panigel; E. Meyer, Int J Nucl Med BIol 1973, 1, (2), 4.

93. T. Tsuchiya; I. Oguri; Y. Yamakoshi; N. Miyata, FEBS Letters 1996, 393, (1), 7.

94. B. Ballou; B. C. Lagerholm; L. A. Ernst; M. P. Bruchez; A. S. Waggoner, Bioconjugate Chemistry 2003, 15, (1), 79-86.

95. V. Wiwanitkit; A. Sereemaspun; R. Rojanathanes, in: Fertil Steril, 2007.

96. S. Yoshida; K. Hiyoshi; T. Ichinose; H. Takano; S. Oshio; I. Sugawara; K.

Takeda; T. Shibamoto, in: Int J Androl, January 22: 2008.

97. T. Tsuchiya; Y. Yamakoshi; N. Miyata, Biochem Biophys Res Comm 1995, 206, (3), 10.

98. OSHA Medical Screening and Surveillance. http://www.osha.gov/SLTC/medicalsurveillance/index.html (1/29/08), 
99. D. Evans; W. Heitbrink; T. Slavin; T. Peters, Annals of Occupational Hygiene 2008, 52, (1), 13.

100. C. Tsai; E. Ada; M. Ellenbacker; M. Hallock; K. Ahn, in: CampusHealth Safety and environmental Management, Boston, 2007.

101. W. Heitbrink; D. Evans; T. Peters; T. Slavin, Journal of Occupational and Environmental Hygiene 2007, 4, (5), 11.

102. D. Brouwer; J. Gijsbers; M. Lurvink, Annals of Occupational Hygiene 2004, 48, (5), 15.

103. H. Fissan; S. Neumann; A. Trampe; D. Pui; W. SHin, Journal of Nanoparticle Research 2007, 9 , 7.

104. H. C. Wang; G. Kasper, Journal of Aerosol Science 1991, 22, 11.

105. A. Balazy; A. Podgorskyi; L. Gradon in: Filtration of nanosized aerosol particles in fibrous filters. I-Experimental results, European Aerosol Confreence, 2004, 2004; 2004; p 2.

106. E. A. Bal; C. v. Guliji in: Measurement of aerosol filtration for ultrafine particles, European Aerosol Conference, 2004; Thermap rebound measurement theory: 2004; pp 979-980.

107. A. Balazy; M. Toivola; T. Reponen; A. Podgorsky; A. Zimmer; S. Grinshpun, Annals of Occupational Hygiene 2005, Baazy 2005 REspirators 12.

108. B. Halford, Chemical \& Engineering News 2006, 84, (18), 1.

109. M. Heim; B. Mullins; M. Wild; J. Meyer; G. Kasper, Aerosol Science and Technology 2005, 39, $(8), 8$.

110. C. S. Kim; L. Bao; K. Okuyama; M. Shimada; H. Niinuma, Journal of Nanoparticle research 2006, 8, (2), 7 .

111. D. Japuntich; L. Franklin; D. Pui; T. Kuehen; S. C. Kim; A. Viner, Journal of Nanoparticle Research 2007, 9, 15.

112. J. Wang; D. Chen; D. Pui, Journal of nanoparticle research 2007, 9, 7.

113. S. C. Kim; M. Harrington; D. Pui, Journal of Nanoparticle Research 2007, 9, 9.

114. 3M, 3M Technical Data Bulletin 2006, 171, 6.

115. S.-H. Huang; C.-W. Chen; C.-P. Chang; C.-Y. Lai; C.-C. Chen, Journal of Aerosol Sciences 2007, $38,(7), 9$. 
116. M.-H. Lee; W. Mcclellan; J. Candela; D. Andrews; P. Biswas, Journal of Nanoparticle REsearch 2007, 9, 10.

117. NIOSH, in: N. I. f. O. S. a. Health, (Ed.) Department of Health and Human Services: 2007.

118. R. Russel; R. Cresanti, in: N. S. a. T. COuncil, (Ed.) 2006.

119. M. Nasterlack; A. Zobor; C. Oberlinner, Int Arch Occup Environ Health 2007, Published online September 12, 2007, 6. 